\title{
PREVALÊNCIA DE MARCADORES SOROLÓGICOS DO VÍRUS DA HEPATITE B (HBV) NOS MUNICÍPIOS DE URBANO SANTOS, AXIXÁ, HUMBERTO DE CAMPOS, MORROS E ICATU: RESULTA- DOS PARCIAIS DE UM ESTUDO DE BASE POPULACIONAL.*
}

\author{
PREVALENCE OF SEROLOGIC MARKERS OF HEPATITIS B VIRUS (HBV) IN \\ THE TOWNS OF URBANO SANTOS, AXIXÁ, HUMBERTO DE CAMPOS, MOR- \\ ROS AND ICATÚ: PARTIAL RESULTS OF A POPULATIONAL SURVEY.
}

PREVALENCIA DE MARCADORES SEROLÓGICOS DEL VIRUS DE HEPATITIS B (HBV) EN LOS MUNICIPIOS DE URBANO SANTOS, AXIXÁ, HUMBERTO DE CAMPOS, MORROS E ICATÚ: RESULTADOS PARCIALES DE UN ESTUDIO CON BASE EN LA POBLACIÓN.

\author{
Camila Maia Valente \\ Acadêmica do curso de Medicina da Universidade Federal do Maranhão \\ Adalgisa de Souza Paiva Ferreira \\ Doutora em Gastroenterologia da Universidade Federal do Maranhão \\ Ludmilla Emília Martins Costa \\ Acadêmica do curso de Medicina da Universidade Federal do Maranhão \\ Lena Maria Barros Fonseca \\ Doutora em Biotecnologia da Universidade Federal do Maranhão \\ Max Diego Cruz Santos \\ Bolsista do CNPq - Brasil \\ Jomar Diogo Costa Nunes \\ Mestre em Saúde Materno Infantil do Centro de Pesq. Clínica do Maranhão \\ Marinilde Telles Souza \\ Enfermeira especialista do Centro de Pesquisa Clínica do Maranhão \\ Maria Josélia Diniz Moraes \\ Enfermeira especialista do Centro de Pesquisa Clínica do Maranhão
}

\begin{abstract}
RESUMO: As hepatites virais são doenças que apresentam distribuição universal. No Brasil, há grande variação regional na prevalência de cada hepatite. A prevalência da infecção pelo vírus da hepatite $B$ (HBV) nas capitais do Nordeste é de $0,5 \%$. Não há informações sobre a prevalência desta infecção no estado do Maranhão. Em estudo realizado no ano de $2010 \mathrm{com}$ pacientes do Maranhão observou-se que muitos portadores do HBV eram provenientes dos municípios de Urbano Santos, Axixá, Morros, Icatu e Humberto de Campos. Esta maior frequência também já vinha sendo observada pelo Programa de Hepatites Virais da Secretaria Estadual de Saúde. Essas observações sugerem que esta é uma região onde a prevalência do HBV pode ser maior que a descrita para a região Nordeste do Brasil. Este trabalho objetiva identificar os indivíduos com sorologia positiva para os marcadores do HBV (HBsAg, anti-HBc total e anti-HBs). Trata-se de um estudo de prevalência com base em uma população definida. A amos-tra é composta por 4.000 pessoas residentes nos municípios citados. Os pacientes foram entrevistados mediante um questionário epidemiológico, demográfico e clínico. Posteriormente foram coletadas amos-tras de sangue para realização dos exames sorológicos e moleculares. Das 871 amostras testadas até o momento, a prevalência do HBsAg foi de $2.99 \%$. As prevalências de anti-HBc total e anti-HBs foram $32.53 \%$ e $40.34 \%$, respectivamente. AntiHBs isoladamente positivo esteve presente em 19.63\%. Esta
\end{abstract}

\footnotetext{
* Trabalho premiado durante o XXV Encontro do SEMIC, realizado na UFMA, entre os dias 18 a 22 de novembro de 2013. Artigo recebido em fevereiro de 2014

Aprovado abril de 2014
} 
prevalência do HBsAg identificada até o momento sugere que aquela região tenha uma endemicidade intermediária para infecção crônica pelo HBV.

Palavras-chave: Hepatite. Prevalência. Maranhão.

ABSTRACT: Viral hepatitis is a disease that presents universal distribution. In Brazil there is substantial regional variation in the prevalence of each hepatitis. The prevalence of infection with hepatitis $B$ virus (HBV) in the capitals of the Northeast is $0.5 \%$. There is no information about the prevalence of this infection in the state of Maranhão. In a study conducted in 2010 patients with Maranhão be noted that many HBV carriers were from the cities of Urbano Santos, Axixá, Morros, Icatu and Humberto de Campos. This increased frequency also was already being observed by the State Department of Health Viral Hepatitis Program. These observations suggest that this is a region where the prevalence of HBV may be greater than that described for the Northeast region of Brazil. This paper intends to identify individuals with positive serology for HBsAg markers, anti-HBc and anti-HBs in HBV. This is a prevalence study based on a defined population. The sample consists of 4,000 people living in that cities. Patients were interviewed using an epidemiological, demographic and clinical questionnaire. Subsequently, blood samples were collected to measure the serological and molecular tests. Among 871 samples examined so far, the prevalence of HB-sAg was $2.99 \%$ so far. The prevalence of anti-HBc and anti-HBs were $32.53 \%$ and $40.34 \%$, respectively. Positive isolated anti-HBs was present in $19.63 \%$. This prevalence of $\mathrm{HBV}$ infection, detected so far in the study, identifies this region as intermediate endemicity.

KEYWORDS: Hepatitis. Prevalence. Maranhão State.

RESUMEN: Las hepatitis virales son enfermedades que presentan distribución universal. En Brasil, hay gran variación regional en la prevalencia de cada hepatitis. La prevalencia de la infección por el virus de hepatitis B (HBV) en las capitales del Nordeste es de 0,5\%. No hay informaciones sobre la prevalencia de esta infección en el Estado de Maranhão. En estudio realizado en el año de 2010 con pacientes de Maranhão se observó que muchos portadores de HBV eran provenientes de los municipios de Urbano Santos, Axixá, Morros, Icatú y Humberto de Campos. Esta mayor frecuencia también ya estaba siendo observada por el Programa de Hepatitis Virales de la Secretaría Estadual de Salud. Estas observaciones sugieren que esta es una región donde la prevalencia de la HBV puede ser mayor que la descrita para la región Nordeste de Brasil. Este trabajo busca identificar a los individuos con serología positiva para los marcadores HBsAg, anti$\mathrm{HBc}$ total y anti-HBs de la HBV. Se trata de un estudio de prevalencia con base en una población definida. La muestra es compuesta por 4.000 personas residentes en los municipios de Urbano Santos, Axixá, Humberto de Campos, Morros e Icatú. Los pacientes fueron entrevistados me-diante un cuestionario epidemiológico, demográfico y clínico. Posteriormente fueron recogidas muestras de sangre para realización de los exámenes serológicos y moleculares. De las 871 serologías realizadas, la prevalencia de HBsAg fue de $2.99 \%$. Las prevalencias de anti-HBc Total y anti-HBs fueron $32.53 \%$ y $40.34 \%$, respectivamente. Anti-HBs aisladamente positivo estuvo presente en $19.63 \%$. La prevalencia de

2.99\% de la infección por la HBV, detectada hasta el momento por el estudio, identifica esta región como de endemicidad intermediaria.

PALABRAS CLAVE: Hepatitis. Prevalencia. Maranhão. 
PREVALÊNCIA DE MARCADORES SOROLÓGICOS | Camila Maia Valente et al.

\section{1 | Introdução}

As hepatites virais são doenças provocadas por diferentes agentes etiológicos que apresentam características epidemiológicas, clinicas e laboratoriais semelhantes, porém com importantes particularidades. Têm uma distribuição universal, com a magnitude dos diferentes tipos variando com a região do globo. No Brasil, também ha grande variação regional na prevalência de cada hepatite (BRASIL, 2008).

A Hepatite $B$ permanece como significativo problema de saúde pública mundial, com amplo impacto pessoal, econômico e social. A Organização Mundial da Saúde (OMS) estima que 350 milhões de pessoas vivam com o vírus da hepatite $B(H B V)$.

A prevalência do HBsAg (antígeno de superfície do HBV) nas capitais da região Nordeste do Brasil, baseado em inquérito nacional é 0,5 (BRASIL, 2010). Outros estudos regionais têm mostrado taxas de infecção pelos vírus $B$ variando de $21 \%$ em Manaus e 1,2\% em Fortaleza (PAULA et al., 2001; EL KHOURI et al., 2010). A Infecção pelo HBV é considerada endêmica em algumas áreas da região amazônica (MADDREV, 2001; EL KHOURI et al., 2010), em especial na Amazônia Ocidental, em uma área correspondente aos Estados do Acre, Amazonas, Rondônia e Roraima (EL KHOURI et al., 2010).

$O$ vírus $B$ é transmitido através da exposição de mucosas ou do contato percutâneo com san-gue ou outros fluidos corporais contaminados (MATOS et al, 2007). As maiores concentrações do HBV são encontradas no sangue e no soro, entretanto, fluidos corporais derivados deste último, como sêmen e saliva, também são infectivos (SHEPARD, 2006). Indivíduos com hepatite B crô-nica representam o principal reservatório de transmissão, embora qualquer pessoa com HBsAg positivo seja potencialmente infectiva (SHEPARD, 2006). As principais vias de transmissão do HBV são sexual, percutânea, perinatal, horizontal, transfusão, infecção nosocomial e transplante de órgãos (WASMUTH, 2009).

A infecção crônica causada pelo HBV é responsável por uma das principais causas de cirrose hepática no Brasil, trazendo prejuízos incalculáveis para os serviços de saúde do país. Especifi-camente, não há informações sobre prevalências destas infecções no estado do Maranhão, que está localizado na Amazônia Legal e pela proximidade com áreas de alta endemicidade do Brasil para o HBV, necessitando assim de estudos para defini-las.

Em estudo realizado no ano de 2010 com pacientes do Maranhão em colaboração com o Laboratório de Medicina Tropical do Departamento de Gastroenterologia da Universidade de São Paulo (USP), observou-se que muitos portadores do HBV eram provenientes dos municípios de Urbano Santos, Axixá, Morros, Icatu e Humberto de Campos. Esta maior frequência também já vinha sendo observada pelo Programa de Hepatites Virais da Secretaria Estadual de Saúde.

Essas observações sugerem que esta é uma região onde a prevalência do HBV pode ser maior que a descrita para a região Nordeste do Brasil.

Especificamente, não há informações sobre a prevalência desta infecção no estado do Mara-nhão. Dessa forma, propomos realizar uma investigação de base populacional para identificar os indivíduos com sorologia positiva para os marcadores HBsAg, anti-HBc e anti-HBs do vírus da Hepatite B.

\section{2 | Metodologia}

Trata-se de um estudo de prevalência com base em uma população definida, realizado nos municípios maranhenses de Urbano Santos, Axixá, Humberto de Campos, Morros e Icatú, no período de Janeiro de 2011 a dezembro de 2013.

A amostra é composta por 4.000 pessoas com idade mínima de um ano. Para calcular a amos- 
tra foi adotada uma prevalência de $0,5 \%$ do $\mathrm{HBsAg}$ (considerando o resultado da prevalência do $\mathrm{HBsAg}$, encontrada no inquérito nacional na região nordeste) com erro absoluto de $0,3 \%$, nível de confiança de $95 \%$ assumindo um efeito de desenho de $2=a 1.928$ pessoas, com uma amostra total de 3.856 a 4.000 indivíduos. A amostragem foi feita por conglomerado em dois estágios: no primeiro foram sorteados os setores com probabilidade proporcional à população. No segundo, foram sorteados os quarteirões.

As entrevistas foram realizadas mediante um questionário epidemiológico, demográfico e clínico. Posteriormente, foram coletadas amostras de sangue, aliquotadas em duplicata e conservadas em freezer a $-70^{\circ} \mathrm{C}$, para realização dos exames sorológicos e moleculares.

Os exames sorológicos (HBsAg, anti-HBc total e anti-HBs) estão sendo realizados no Laboratório Central do Estado do Maranhão (LACEN), através da técnica do ensaio imunoenzimático (ELISA) utilizando kits comerciais da DIASORIN. Serão também realizados os testes de biologia molecular (HBV-DNA e genotipagem) no Centro de Pesquisa Clínica do Hospital Universitário da Universidade Federal do Maranhão CEPEC-HUFMA), com a colaboração do Laboratório de Gastroenterologia e Hepatologia Tropical da Faculdade de Medicina da Universidade de São Paulo (LGHT-FM/USP).

Em cumprimento aos requisitos exigidos pela Resolução 196/96, do Conselho Nacional de Saúde, o Projeto foi aprovado pelo Comitê de Ética em Pesquisa da Universidade Federal do Maranhão, sob o parecer número 053/2012.

\section{3 | Resultados}

Dos 2.680 dados coletados até o momento, 536 são do município de Axixá, 804 foram coleta-dos no município de Morros, 1.072 em Humberto de Campos e 268 em Icatu. Destes, 532 ques-tionários preenchidos no município de Axixá e 904 em Humberto de Campos foram digitados e analisados, totalizando 1430 dados, sendo os resultados parciais:

A maioria dos dados foi coletada na zona rural $(61.43 \%)$ e $38.57 \%$ foram coletados na zona urbana dos municípios estudados.

A média de idade e desvio padrão foi de 28 anos \pm 20 . A idade mínima foi um ano e a máxima 92 anos. Dos entrevistados, $42.67 \%$ eram do sexo masculino. Quanto ao grau de instrução, observou-se que maioria (50.24\%) tinha ensino fundamental incompleto, um percentual de $7.17 \%$ de analfabetos e apenas $2.64 \%$ dos indivíduos concluíram o ensino superior.

De acordo com a impressão do entrevistador, $63.94 \%$ dos indivíduos eram pardos, $15.36 \%$ pretos e $18.62 \%$ brancos. Mais de $50 \%$ dos entrevistados eram solteiros, $15.45 \%$ eram casados e $20.53 \%$ viviam em união estável. Foi observada uma predominância de católicos (75.43\%) sobre os sem religião (7.52\%) e evangélicos (13.36\%).

A maior parte dos entrevistados (49.34\%) possuía renda entre um e três salários mínimos, enquanto $46 \%$ apresentavam renda inferior a um salário mínimo, e apenas $3.48 \%$ tinham renda superior a três salários mínimos.

Até o momento foram realizadas as sorologias de 871 amostras coletadas, sendo 210 do município de Axixá, 173 de Morros e 488 de Humberto de Campos. As demais ainda estão em processo de realização e análise.

Entre as 871 sorologias realizadas, a prevalência de $\mathrm{HBsAg}$ foi de $2.99 \%$. As prevalências de anti-HBc total e anti-HBs foram $32.53 \%$ e $40.34 \%$, respectivamente. Anti-HBs isoladamente positivo esteve presente em $19.63 \%$.

Os demais dados já coletados ainda estão em processo de digitação e os testes sorológicos estão em processo de execução no LACEN. 
PREVALÊNCIA DE MARCADORES SOROLóGICOS | Camila Maia Valente et al.

Tabela 1 - Características sócio-demográficas dos entrevistados nos municípios de Axixá e Humberto de Campos-MA, em 2012-13.

\begin{tabular}{|c|c|}
\hline Características & $\begin{array}{c}\text { Pacientes }(\mathrm{n}=1.430) \\
\%\end{array}$ \\
\hline Idade (anos, média $\pm D^{*}$ ) & $28 \pm 20$ \\
\hline \multicolumn{2}{|l|}{ Gênero } \\
\hline Masculino & 42.67 \\
\hline Feminino & 57.33 \\
\hline \multicolumn{2}{|l|}{ Grau de instrução } \\
\hline Analfabeto & 7.17 \\
\hline Ensino fundamental & 50.24 \\
\hline Ensino fundamental & 8.14 \\
\hline Ensino médio incompleto & 11.06 \\
\hline Ensino médio completo & 14.96 \\
\hline Ensino superior & 0.90 \\
\hline Ensino superior completo & 2.64 \\
\hline \multicolumn{2}{|l|}{ Cor } \\
\hline Pardo & 63.94 \\
\hline Preto & 15.36 \\
\hline Branco & 18.62 \\
\hline Outra & 2.08 \\
\hline \multicolumn{2}{|l|}{ Estado conjugal } \\
\hline Solteiro & 58.32 \\
\hline Casado & 15.45 \\
\hline Separado judicialmente & 0.49 \\
\hline Divorciado & 0.63 \\
\hline Viúvo & 3.41 \\
\hline União estável & 20.53 \\
\hline \multicolumn{2}{|l|}{ Religião } \\
\hline Nenhuma & 7.52 \\
\hline Católica & 75.43 \\
\hline Evangêlica & 13.36 \\
\hline Outra & 1.18 \\
\hline \multicolumn{2}{|l|}{ Renda familiar } \\
\hline Menos de $1 \mathrm{SM}^{* *}$ & 46.00 \\
\hline 1 a $3 \mathrm{SM}^{* *}$ & 49.34 \\
\hline 4 a $6 \mathrm{SM}^{* *}$ & 3.41 \\
\hline
\end{tabular}

Fonte: Elaborado pelos autores 
PREVALÊNCIA DE MARCADORES SOROLÓGICOS | Camila Maia Valente et al.

Tabela 12- Características sorológicas dos entrevistados nos municípios de Axixá, Morros e Humberto de Campos--MA, em 2012-13.

\begin{tabular}{lcc}
\hline Sorologias & \multicolumn{2}{c}{ Pacientes $(\mathrm{n}=871)$} \\
n & $\%$ \\
HBsAg & & \\
Negativo & 833 & 95.64 \\
Positivo & 26 & 2.99 \\
Ignorado & 12 & 1.38 \\
Anti-HBc Total & & \\
Negativo & 572 & 65.67 \\
$\quad$ Positivo & 283 & 32.50 \\
Ignorado & 16 & 1.83 \\
Anti-HBs & & \\
$\quad$ Negativo & 425 & 48.80 \\
Positivo & 351 & 40.30 \\
Ignorado & 95 & 10.90 \\
Anti-HBs isoladamente positivo & 171 & 19.63 \\
\hline
\end{tabular}

Fonte: Elaborado pelos autores

\section{4 | Considerações finais}

Prevalência da infecção pelo HBV em torno de $3 \%$, detectada até o momento pelo es-tudo, identifica esta região como de endemicidade intermediária. Essa informação é de grande relevância, já que, de acordo com o Ministério da Saúde, a região Nordeste do Brasil é considerada de baixa prevalência para a infecção pelo HBV $(<1 \%)$ (BRASIL, 2010). Outros estudos brasileiros, envolvendo populações de áreas rurais, já têm demonstrado maiores prevalências do HBsAg (ANASTÁCIO, 2008).

Dessa forma, se os resultados finais seguirem os aqui descritos, medidas efetivas de preven-ção da infecção devem ser urgentemente implementadas na região estudada, com destaque para o aumento da cobertura vacinal e campanhas para incentivar o uso de preservativos, já que umas das principais vias de transmissão da Hepatite B é sexual. 


\section{Referências}

ANASTÁCIO, J. et al. Prevalência do vírus da hepatite $B$ em indivíduos da região do centro ocidental do Paraná, Brasil. Revista de Saude e Biologia, Campo Mourão, v. 3, n. 2, p. 10-15, 2008.

BLANCHET, M. \& SUREAU, C. Analysis of the cytosolic domains of the hepatitis B virus envelope proteins for their function in viral particle assembly and infectivity. J. Virol. v. 80, p. 11935-11945, 2006.

BRASIL. Secretaria de Vigilancia em saúde. Ministério da Saúde. Departamento de DST, AIDS e Hepatites Virais. Estudo de prevalência de base populacional das infecções pelos vírus das hepatites $A, B$ e $C$ nas capitais do Brasil. Universidade de Pernambuco, Brasília, DF: [s.n.], 2010, 211p.

Departamento de Vigilância Epidemio-

lógica. Hepatites virais: o Brasil está atento. 3.ed.

Brasília, DF: Ministério da Saúde, 2008. 60p.

(Série B. Textos básicos de saúde).

PAULA, V. S. de. et al. Seroprevalence of viral hepa-titis in riverine communities from the Western Region of the Brazilian Amazon Basin. Mem Inst Oswaldo Cruz., v. 96, n. 8, p. 1123-8, Nov. 2001.

El KHOURI, M. et al. Endemic Hepatitis $B$ and $C$ virus infection in a Brazilian eastern Amazon region. Arq Gastroenterol. v. 47, n. 1, p. 35-41, jan./mar. 2010. GOMES-GOUVÊA, M. S. et al. Hepatitis D and B virus genotypes in chronically infected patients from the Eastern Amazon Basin. Acta Tropica, v. 106, n. 3, p. 149-155, June 2008.

\section{INSTITUTO BRASILEIRO DE GEOGRAFIA E ESTA-} TÍSTICAS. Município de Urbano Santos. 2009. Disponível em: <http://www.ibge.gov.br/home/mapa_site/ mapa_site.php\#download>. Acesso em: 13 jun. 2010.

Município de Axixá. 2009a. Disponível em: <http://www.ibge.gov.br/home/mapa_site/mapa_site. php\#download.>. Acesso em 25 set. 2010.

. Município de Morros. 2009b. Disponível em: <http://www.ibge.gov.br/home/mapa_site/mapa_site. php\#download.>. Acesso em 25 set. 2010.

Município de Icatú. 2009c. Disponível em: <http://www.ibge.gov.br/home/mapa_site/mapa_site. php\#download>. Acesso em: 25 set. 2010.

Município de Urbano Santos. 2005. Disponível em: <http://www.ibge.gov.br/cidadesat/painel/ painel.php?codmun=211260\#>. Acesso em: 28 jun. 2010.

Município de Axixá. 2005a. Disponível em: <http://www.ibge.gov.br/cidadesat/topwindow.htm?1>. Acesso em: 25 set. 2010.
Município de Morros. 2005b. Disponível em: <http://www.ibge.gov.br/cidadesat/topwindow.htm?1>. Acesso em: 25 set. 2010.

Município de Icatú. 2005c. Disponíve em: <http://www.ibge.gov.br/cidadesat/topwindow.htm?1>. Acesso em: 25 set. 2010.

Município de Axixá. 2003. Disponível:

<http://www.ibge.gov.br/cidadesat/topwindow.htm?1>. Acesso em: 25 set. 2010.

Município de Morros. 2003a. Disponível em: <http://www.ibge.gov.br/cidadesat/topwindow.htm?1>. Acesso em: 25 set. 2010.

Município de Icatú. 2003b. Disponível em: <http://www.ibge.gov.br/cidadesat/topwindow.htm?1>. Acesso em: 25 set. 2010.

LAVANCHY, D. Chronic viral hepatitis as a public health issue in the world. Best pract Res Clin Gastroenterol., v. 22, n. 6, p. 991-1008, 2008.

MADDREY, W. C. Hepatitis B and important public health issue. Clin Lab., v. 47, p. 51-55, 2001.

MARCHESINI, A. M. et al. Hepatites B e C em usuários de drogas injetáveis vivendo com HIV em São Paulo, Brasil. Rev. Saúde Pública, São Paulo, v. 41, dez. dec. 2007.

MATOS, C. A. et al. Epidemiologia das hepatites virais. In: MISZPUTEN, Sender J. (Coord.) Guia de Gastroenterolgia. 2.ed. Barueri: Manole, 2007. cap. 10, p. 84. (Guias de medicina ambulatorial e hospitalar da Unifesp - EPM).

REIS, J. L. C. Potencialidades econômicas do Estado do Maranhão. São Luís: SEPLAN/IMESC, 2008. 19 p. (Série estudos de regionalização, n.4).

MARANHÃO. Secretaria de Estado do Planejamento e Orçamento. Instituto Maranhense de Estudos Socioeconômicos e Cartográficos. Potencialidades econômicas do Maranhão: estudos de regionalização n. 4. São Luís: SEPLAN/IMESC, 2008.

SHERPARD, C. W. et al. Hepatitis B virus infection: epidemiology and vaccination. Epidemiologic Re-views, n. 28, p.112-125, 2006. WASMUTH, Jan-Christian. Hepatite B. In: BERG, Thomas et al. (Ed.). Hepatology: a clinical text book. Germany: Flying Publisher, 2009. cap.2 e 3, p.25-34 e 37-40. Disponível em: <www.hepatologytextbook. com>. Acesso em: 25 set.2010.

WORLD HEALTH ORGANIZATION. Hepatitis B. Disponível em: <http:// www.who.int/vaccines-diseases/diseases/hepa titis_b.htm>. Acesso em: 15 mar. 2005. 